Gut, 1982, 23, 326-332

\title{
Comparison of the composition of faecal fluid in Crohn's disease and ulcerative colitis*
}

\author{
R SCHILLI, R I BREUER, † F KLEIN, KAY DUNN, AGNES GNAEDINGER, J BERNSTEIN, \\ M PAIGE, AND M KAUFMAN
}

From the Department of Medicine, Division of Gastroenterology Evanston Hospital, Evanston, and North-western University Medical School, Chicago, Illinois, USA

SUMMARY We determined the ionic composition of faecal fluid from 13 patients with Crohn's disease limited to the colon, 10 with diffuse ulcerative colitis, and eight with ulcerative proctitis. The Crohn's and colitis groups had similar proportions of colon surface involved radiographically and similar 24 hour faecal weights. However, Crohn's patients' faecal fluid had arithmetically lower mean sodium and statistically lower mean chloride $(34.8 \mathrm{mmol} / 1 \pm 16.2 \mathrm{SD}$ vs. $53.1 \mathrm{mmol} / 1 \pm 23 \cdot 1$ SD) and higher potassium (49.2 mmol/1 $\pm 20.2 \mathrm{SD}$ vs. $33.0 \mathrm{mmol} / 1 \pm 13.8 \mathrm{SD})$ concentrations (P $<0.05$ for each) and much higher osmolality $(487.1 \mathrm{mOsmol} / \mathrm{kg} \pm 87.1 \mathrm{SD}$ vs. $341.1 \mathrm{mOsmol} /$ $\mathrm{kg} \pm 88.9 \mathrm{SD}, \mathrm{P}<0.001)$. Separation of these patients using the faecal osmotic gap agreed with the clinical classification in $86 \%$ of cases. The diarrhoea of proctitis patients had a nearly normal ionic composition which was clearly distinguishable from that of diffuse colitis. These results suggest differences in the composition and perhaps the pathogenesis of the diarrhoea of Crohn's and ulcerative colitis. The composition of fluid may prove a useful, non-invasive method for classifying patients with inflammatory bowel disease and, in ulcerative colitis, determining the extent of the inflammatory process.

Diarrhoea is a major symptom of non-specific inflammatory bowel disease. When we analysed faecal fluid in a variety of disease states, we noticed differences between the composition of diarrhoea from patients with Crohn's disease of the colon and that from patients with chronic ulcerative colitis. The present retrospective study was designed to see if the osmolality and ionic composition of the faecal fluid from these groups of patients were, indeed, different. We also studied the faecal effluent from patients with chronic ulcerative colitis limited to the rectosigmoid to see if it differed from that of patients with more extensive colitis.

\section{Methods}

\section{SELECTION AND CLASSIFICATIONOF} PATIENTS

The patients were those whom the managing clinicians at Evanston Hospital suspected of having inflammatory bowel disease involving the colon and who had had

\footnotetext{
*This work was supported by a grant from Dee and Moody Fund, Evanston Hospital.

† Address for reprint requests: Dr Richard I Breuer, Department of Medicine, Evanston Hospital, 2650 Ridge Avenue, Evanston, IL 60201, USA.

Received for publication 3 August 1981
}

faecal collections. A prior diagnosis of this disorder may have been established; however, we included only those patients whose faecal collections had been performed when they had had no anti-inflammatory therapy for at least six weeks. None was using diuretics or other agents with known effects on water and electrolyte balance. All patients had diarrhoea as a prominent symptom during this period, designated hereafter as the 'index clinical attack'.

All patients were assigned to one of the following groups: ulcerative proctitis-defined as ulcerative colitis limited to the rectum and sigmoid, chronic ulcerative colitis, or Crohn's disease of the colon. Assignment depended on either unanimous agreement or on a consensus arrived at at a conference after independent review by our clinicians (RS, RB), radiologists (JB, $\mathrm{MP}$ ), and pathologist (MK) investigators.

The clinicians individually reviewed all data available including clinical records, descriptions of endoscopic findings, radiographs, and pathological material. For each patient they recorded: age, sex, race, presence of prior inflammatory bowel disease and its duration, history of prior anti-inflammatory therapy, duration of symptoms before faecal collection, length of hospitalisation, weight loss, presence of blood in the 
stool, extraintestinal symptoms, and abdominal pain. Laboratory data recorded were white blood count, haemoglobin, haematocrit, sedimentation rate, serum albumin, and stool cultures. Dietary fat and caloric intake were recorded from dieticians' records. Additional information required for inclusion in the study included a report of at least one endoscopic examination (proctosigmoidoscopy, fibresigmoidoscopy, or colonoscopy) with biopsy performed during the index clinical attack, as well as barium contrast radiographs taken within six weeks of this attack. We excluded any patient with a specific enteric pathogen or for whom any diagnosis other than non-specific inflammatory bowel disease was established.

The two radiologists reviewed all radiographs available on each patient independently of each other and without knowledge of the clinical or pathological findings. Films reviewed included full column or air contrast barium upper gastrointestinal, small bowel follow through, and colon examinations. All prior or subsequent available radiographs were also reviewed. The criteria used for the diagnosis of Crohn's disease of the colon and chronic ulcerative colitis were those generally accepted and well described in the current literature. ${ }^{1-4}$ The linear extent and location of disease was measured in each case by a planimeter applied directly to the radiograph and by shading a schematic drawing of the colon. Any patient having concurrent, prior, or subsequent radiographic involvement of the ileum was also excluded.

The pathologist reviewed all available pathological material without knowledge of the clinical or radiographic findings. The material included biopsies from proctoscopic, fibresigmoidoscopic, and colonoscopic examinations performed before, during, and after the index clinical attack, as well as from resected specimens of bowel obtained after the index period. Where the pathological diagnosis was uncertain, a consultant pathologist (Dr R Riddell, University of Chicago) independently reviewed the slides and gave an opinion. Accepted histopathological criteria for classifying and differentiating specimens as chronic ulcerative colitis or Crohn's disease of the colon were used. ${ }^{2}$ 7

\section{FAECAL COLLECTIONS AND ANALYSES}

Only faecal collections performed during the index clinical attack were used for this study. Analyses were performed on consecutive 24,48 , or 72 hour specimens which were refrigerated immediately after passage in one gallon paint cans prepared with $15 \mathrm{ml} \mathrm{1:10000}$ thimerosal as a bacteriostatic agent. The samples were stored frozen at $-20^{\circ} \mathrm{C}$ until analysed. Thawed or freshly collected stool was homogenised while cold, deionised water was added when necessary. Aliquots were dried for 48 hours in an oven at $70^{\circ} \mathrm{C}$, and percentage moisture determined gravimetrically. Fat was measured by a modification of the method of Van De Kamer. ${ }^{8}$ A filtrate of stool was prepared by centrifugation at $+4^{\circ} \mathrm{C}$ at $1000 \mathrm{~g}$ through a 50000 Dalton membrane (Amicon Company; Lexington, Mass.). The stool was analysed for sodium and potassium by flame photometry (IL 143 Flame Photometer); chloride by potentiometric titration (Buchler Chloridometer); and osmolality by freezing point depression (Advanced Instruments). The 'osmotic gap', defined as the measured osmolality minus $2\left(\left[\mathrm{Na}^{+}\right]+\left[\mathrm{K}^{+}\right]\right)$, as well as the $\left[\mathrm{K}^{+}\right] /\left[\mathrm{Na}^{+}\right]$ratio were calculated.'

For each of the 31 patients with untreated inflammatory bowel disease who had been classified as chronic ulcerative colitis, Crohn's disease of the colon, or ulcerative proctitis we analysed 24 hour stool specimens that had been collected for one, two, or three consecutive days. Using the data from any single day or any combination of multiple days' collections resulted in similar comparisons among the groups. Therefore, for simplicity, we present the results of the analysis from the day with highest faecal weight for each patient. The results of faecal analyses from 11 normal patients previously analysed in our laboratory, which were similar to data published by other laboratories, were used as reference standards. ${ }^{1011}$

The major statistical methods used were the $t$ test and the Mann-Whitney U test. ${ }^{12}$

\section{Results}

CLASSIFICATION OF PATIENTS

Thirty-eight of 50 patients suspected of inflammatory bowel disease met the criteria listed in the Methods section. Of these 38 patients, our clinicians agreed on the classification of 36 . The radiologists agreed on 32 patients, differed on four, and classified two as having radiographic features of both Crohn's disease of the colon and chronic ulcerative colitis-that is, indeterminate colitis. ${ }^{5}$ The pathologist and his consultant agreed on 36 patients, and classified two as having features of both illnesses. For a patient to be classified as ulcerative proctitis, all investigators had to agree at a subsequent conference that there was no involvement beyond the rectosigmoid. At the conference, all material was reviewed by all investigators. Five of the 38 patients were excluded when the radiologists found that each had minor involvement of the terminal ileum. Of the remaining 33 patients, our group could not agree on two. These were also excluded. Thus, we unanimously classified 13 patients as Crohn's disease of the colon, 10 as chronic ulcerative colitis, and eight as ulcerative proctitis.

CLINICAL COMPARISON OF STUDYGROUP Clinical, historical, dietary, and laboratory variables referred to in the Methods section were similar for the 
Crohn's disease of the colon and chronic ulcerative colitis patients. For the Crohn's disease patients, the mean serum albumin was $34 \mathrm{~g} / \mathrm{l}(3.4 \mathrm{~g} / \mathrm{dl})$; for chronic ulcerative colitis, $27 \mathrm{~g} / \mathrm{l}(2.7 \mathrm{~g} / \mathrm{dl})(\mathrm{P}=0.003)$. The mean percentage of the entire colon surface involved with the inflammatory process, determined radiographically, was similar for these two groups: $71.2 \% \pm 29.25$ for Crohn's disease of the colon, and $82.8 \% \pm 16.98$ for chronic ulcerative colitis $(P=0.245)$.
RESULTS OF FAECAL ANALYSIS

Comparison of study groups with normal subjects

For both Crohn's disease of the colon patients and those with chronic ulcerative colitis the mean 24 hour faecal weight was greater than normal. This and all other comparisons of inflammatory bowel disease patients (Table 2) with normal subjects (Table 1) are significant at the 0.05 level. In both inflammatory bowel disease syndromes, mean $\left[\mathrm{Na}^{+}\right]$and $\left[\mathrm{Cl}^{-}\right]$were higher and

Table 1 Comparison of averages and ranges of faecal stool mass and electrolyte concentrations for normal individuals

\begin{tabular}{llll}
\hline & $A^{10}$ & $B^{11}$ & $C^{*}$ \\
\hline Sodium concentration (mmol/l) & 32 & 36 & 33 \\
Potassium concentration (mmol/l) & $(5-112)$ & $(16-83)$ & $(15-75)$ \\
Chloride concentration (mmol/1) & 75 & 99 & $(44-131)$ \\
Osmolality (mOsmol/kg) & $(29-147)$ & $(57-214)$ & $(5-31)$ \\
Total weight (8/24 h) & $16-38)$ & - & 321 \\
Total sodium (mmol/24 h) & 376 & $(336-423)$ & $99-464)$ \\
Total potassium (mmol/24 h) & - & $(46-182)$ & 134 \\
Total chloride (mmol/24 h) & - & $(1-9)$ & $(67-293)$ \\
{$\left[\mathrm{K}^{+}\right] /\left[\mathrm{Na}{ }^{+}\right]$} & - & $(3-21)$ & $(1-8)$ \\
\end{tabular}

* Present study

Table 2 Means, standard deviations, and sample sizes for Crohn's disease of colon (CDC), chronic ulcerative colitis (CUC), and ulcerative proctitis (UP) patients

\begin{tabular}{|c|c|c|c|}
\hline Variable name & $\begin{array}{l}C D C \\
M e a n \\
S D(N)\end{array}$ & $\begin{array}{l}C U C \\
M e a n \\
S D(N)\end{array}$ & $\begin{array}{l}U P \\
\text { Mean } \\
S D(N)\end{array}$ \\
\hline $\begin{array}{l}\text { Total weight }(\mathrm{g} / 24 \mathrm{~h}) \\
\text { Osmolality (mOsmol/kg) } \\
\text { Sodium concentration (mmol/l) } \\
\text { Potassium concentration (mmol/l) } \\
\text { Chloride concentration }(\mathrm{mmol} / \mathrm{l}) \\
\left.\text { Gap }=\text { Osmol-2[ } \mathrm{Na}^{+}\right]-2\left[\mathrm{~K}^{+}\right] \\
\mathrm{pH} \\
{\left[\mathrm{K}^{+}\right] /\left[\mathrm{Na}^{+}\right]} \\
\text {Total sodium (mmol/24 h) } \\
\text { Total potassium (mmol/24 h) } \\
\text { Total chloride (mmol/24 h) } \\
\text { \% Colon involved }\end{array}$ & $\begin{array}{l}474 \cdot 4 \\
209 \cdot 87(13) \\
487 \cdot 1 \dagger \\
87 \cdot 11(13) \\
58 \cdot 8 \\
10 \cdot 43(13) \\
49 \cdot 2^{*} \\
20 \cdot 21(13) \\
34 \cdot 8^{*} \\
16 \cdot 17(13) \\
271 \cdot 1 \dagger \\
98 \cdot 14(13) \\
6 \cdot 59 \\
0.592(13) \\
0 \cdot 898 \\
0 \cdot 470(13) \\
24 \cdot 8 \\
13 \cdot 14(13) \\
20 \cdot 2 \\
12.37(13) \\
15.6 \\
12.97(13) \\
71 \cdot 2 \\
29 \cdot 25(13)\end{array}$ & $\begin{array}{l}559.8 \\
189.66(10) \\
341.1 \\
88.96(10) \\
67.8 \\
20.52(10) \\
33.0 \\
13.85(10) \\
53.1 \\
21.27(10) \\
139.5 \\
55.41(10) \\
6.67 \\
0.663(7) \\
0.554 \\
0.356(10) \\
35.2 \\
17.09(10) \\
15.9 \\
8.90(10) \\
26.9 \\
13.52(10) \\
82.8 \\
16.98(10)\end{array}$ & $\begin{array}{l}234 \cdot 3 \ddagger \\
113 \cdot 61(8) \\
372 \cdot 8 \\
112 \cdot 38(8) \\
28 \cdot 1 \ddagger \\
16 \cdot 72(8) \\
71 \cdot 68 \\
18 \cdot 20(8) \\
19 \cdot 0 \ddagger \\
12 \cdot 14(8) \\
173 \cdot 3 \\
82 \cdot 37(8) \\
6 \cdot 81 \\
0 \cdot 418(7) \\
3 \cdot 6358 \\
2 \cdot 204(8) \\
2 \cdot 5 \ddagger \\
2 \cdot 10(5) \\
9 \cdot 8 \\
5 \cdot 61(5) \\
2 \cdot 2 \ddagger \\
1 \cdot 82(5) \\
-\end{array}$ \\
\hline
\end{tabular}

The index collection selected for each patient was the one with the largest total weight.

* $P+$ value for the CDC vs CUC comparison * less than 0.05, t less than 0.001.

$\ddagger$ The P-value for the CUC vs UP comparison is $¥$ less than $0.05,8$ less than 0.001 .

The comparisons were made using either the $t$ test or the Mann-Whitney $U$ test. The M-W test was used in the cases where either of the two sample sizes was less than 10 . 
$\left[\mathrm{K}^{+}\right]$lower than levels in the normal subjects. Faecal osmolality for chronic ulcerative colitis patients was similar to that for normal subjects, but that for Crohn's disease of the colon was much greater than the normal value. In ulcerative proctitis, the patients' mean faecal weight was also greater than that for normal subjects. However, faecal concentrations for the ions measured were similar to those for normal subjects.

\section{COMPARISON OF PATIENTS WITH CROHN'S DISEASE OF COLON AND CHRONIC \\ ULCERATIVE COLITIS}

Despite similar 24 hour faecal weights for both groups, differences were noted. Faecal fluid from Crohn's disease of the colon patients had slightly lower mean $\left[\mathrm{Na}^{+}\right]$, significantly lower mean $\left[\mathrm{Cl}^{-}\right]$, and higher mean $\left[\mathrm{K}^{+}\right]$than that for chronic ulcerative colitis patients (Table 2 ). The $\left[\mathrm{K}^{+}\right] /\left[\mathrm{Na}^{+}\right]$ratio tended to be higher in the Crohn's patients than in those with chronic ulcerative colitis $(P=0.07)$. The most striking differences between the Crohn's patients and the ulcerative colitis patients were in osmolality and in the osmotic gap (see Methods). In the Crohn's patients, mean values for both were significantly greater than those for chronic ulcerative colitis (Table 2). The values for osmotic gap for these two groups are shown in Fig. 1.

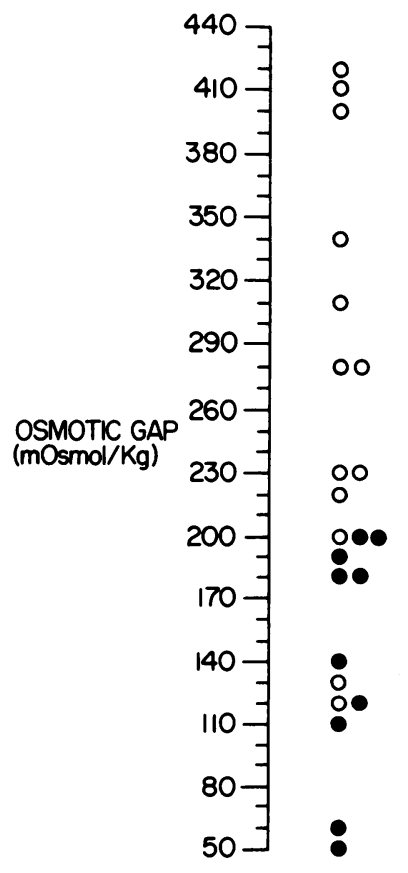

Fig. 1 Distribution of the osmotic gap values for Crohn's disease of the colon (O) and chronic ulcerative colitis (O) patients. Each symbol represents one patient.
The mean osmotic gap for the 23 patients classified as chronic ulcerative colitis or Crohn's disease of the colon by our conference method was 214 . In the construction of Table 3, we used this value as an arbitrary cut-off between the two groups. Separation of patients based on this single characteristic of faecal water agreed with the classification by our conference method in 20 of 23 patients, or $86 \%$.

Table 3 Comparison of 23 patients classified by conference method (see text) and by osmotic gap, defined as osmolality minus $2\left(\left[\mathrm{Na}^{+}\right]+\left[\mathrm{K}^{+}\right]\right)$

\begin{tabular}{lll}
\hline & \multicolumn{2}{l}{ Osmotic gap } \\
\cline { 2 - 3 } & $\leqslant 214$ & $>214$ \\
\hline Chronic ulcerative colitis & 10 & 0 \\
Crohn's disease of the colon & 3 & 10 \\
\hline
\end{tabular}

Comparison of chronic ulcerative colitis and ulcerative proctitis patients

Mean TW. $\left[\mathrm{Na}^{+}\right]$, and $\left[\mathrm{Cl}^{-}\right]$values were higher in chronic ulcerative colitis patients than in those with ulcerative proctitis patients (Table 2). Potassium concentration and the $\left[\mathrm{K}^{+}\right] /\left[\mathrm{Na}^{+}\right]$ratio were lower in the ulcerative colitis patients than in those with ulcerative proctitis: all diffuse colitis patients had cation ratios

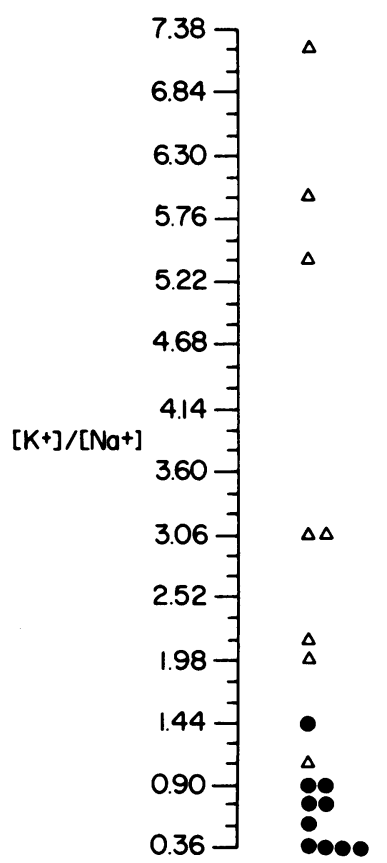

Fig. 2 Distribution of the $\left[\mathrm{K}^{+}\right] /\left[\mathrm{Na}^{+}\right]$ratios for chronic ulcerative colitis $(O)$ and ulcerative proctitis $(\Delta)$. Each symbol represents one patient. 
below the normal range (Table 1), and all but one were lower than the lowest value for ulcerative proctitis (Fig. 2). Twenty four hour losses of sodium and chloride for chronic ulcerative colitis patients were also signifcantly greater than those for ulcerative proctitis (Table 2). Osmolality and $\mathrm{pH}$ were similar for the two groups (P $>0.51$ for each).

\section{Discussion}

Our approach to the diarrhoea of inflammatory bowel disease is relatively simple and has none of the disadvantages of washout techniques for colon perfusion ${ }^{13} 14$ or the necessity for a clean rectal segment as in in vivo rectal dialysis. ${ }^{15}{ }^{16}$ It therefore makes possible the study of all ionic and non-ionic faecal constituents which may be important in the pathogenesis of these patients' diarrhoea. Our data suggest that the diarrhoea from patients with the colonic form of Crohn's disease had a different composition from that of patients with chronic ulcerative colitis. Although the groups had similar proportions of the colonic surface involved radiographically and a similar mean faecal mass, the Crohn's patients had a slightly lower $\left[\mathrm{Na}^{+}\right]$and significantly higher $\left[\mathrm{K}^{+}\right]$than those with chronic ulcerative colitis. Thus, in Crohn's disease of the colon the normal colonic sodium-potassium exchange mechanism appears to be less affected than in chronic ulcerative colitis. The significantly lower $\left[\mathrm{Cl}^{-}\right]$in Crohn's disease of the colon also suggests a lesser disturbance in colonic transport of this ion. The most striking findings were the significantly higher mean osmolality and osmotic gap in Crohn's disease of the colon compared with chronic ulcerative colitis.

What are the explanations for these findings? The faecal electrolyte concentrations and ratios for chronic ulcerative colitis and Crohn's disease of the colon varied in the same direction that would be predicted from faecal volume, alone. However, when the electrolyte concentrations for each patient were adjusted for his or her faecal volume, the differences between the mean values for the two disorders remained apparent. The more severe disturbance of ion transport in chronic ulcerative colitis suggested by the composition of these patients' faecal fluid is consistent with findings demonstrated by more complex methods. Colonic perfusion ${ }^{13}{ }^{14}$ and in vivo rectal dialysis ${ }^{15}{ }^{16}$ have shown that in severe inflammatory bowel disease there is a marked decrease in the absorption of water, sodium, and chloride. In both Crohn's disease of the colon and chronic ulcerative colitis, however, water movement remained linked to transepithelial sodium transport. These studies have also shown that potassium loss was a property of the inflamed mucosa and did not come from desquamated cellular debris. A recent in vivo study also suggested that a deficit in active sodium absorption may con- tribute to the diarrhoea of colonic inflammatory bowel disease. ${ }^{17}$ None of these studies directly compared Crohn's disease of the colon with chronic ulcerative colitis patients. However, comparison of the results from separate colonic perfusion experiments suggests that water, sodium, and potassium transport were more profoundly disturbed in chronic ulcerative colitis than in Crohn's disease of the colon. ${ }^{13} 14$ The relatively preserved ion transport in Crohn's disease of the colon suggested by these earlier studies, as well as by the direct comparison in our study, is consistent with the patchy involvement of the colonic surface in the Crohn's patients documented by many clinical, radiographic, endoscopic, and pathological observations. ${ }^{246}$

The higher osmolality and osmotic gap in Crohn's patients compared with those with chronic ulcerative colitis or normal subjects suggest that additional mechanisms may contribute to the accumulation of faecal water in Crohn's disease of the colon. Several possible explanations for these findings exist. In Crohn's disease, abnormal bile acid secretion, metabolism, and excretion have been demonstrated..$^{18}$ Breath test carbon $^{14}$ and faecal excretion of $\mathrm{C}^{14}$ cholylglycine were higher in 'active' compared with 'inactive' Crohn's disease, ${ }^{19}$ and there was a difference in the response to perfused bile acids in Crohn's disease of the colon patients with severe diarrhoea compared with those with minimal diarrhoea.$^{20}$ Whereas faecal bile acid excretion was normal in one study of chronic ulcerative colitis patients, ${ }^{21}$ there have been no systematic studies of bile acid excretion patterns in Crohn's disease. As the concentration of bile acids in faecal water rarely exceeds $5 \mathrm{mM},{ }^{22}$ altered excretion of these compounds themselves could not explain the striking differences in osmolality or osmotic gap observed in the Crohn's disease patients compared with the ulcerative colitis patients or normal subjects. It is possible that abnormal quantities or unusual forms of bile acids are responsible for the accumulation of other ionic or non-ionic substances which account for the high 'solute gap' found in patients with Crohn's disease of the colon.

Another plausible explanation for these findings would be malabsorption of carbohydrates in these Crohn's disease patients. In carbohydrate intolerance, high concentrations of short-chain fatty acids account for a large solute gap in faecal fluid..$^{23}$ Recently, these acids have been shown to be of importance in the control of faecal volume, as well as ionic transport and $\mathrm{pH}$ in the normal human colon..$^{212}$ These and other studies have suggested a role for the absorption of these compounds in caloric salvage and in moderating faecal volumes and composition in some diarrhoea syndromes. ${ }^{23-25}$

If, indeed, the high solute gap in patients with Crohn's disease of the colon is due to carbohydrate malabsorption, it could be attributed to excessive intake, 
rapid transit, or defective digestion or absorption. Review of our patients' diet histories does not support a difference in caloric intake between the two patient groups. At the time of study, six of 13 of the Crohn's disease patients and five of 10 chronic ulcerative colitis patients were on clear liquid or chemically defined diets which contained no lactose or more general diets from which milk was excluded. The normal and similar mean faecal $\mathrm{pH}$ for the two groups also suggests that lactase deficiency was not the major reason for the high osmolality and solute gap in those with Crohn's disease of the colon. We know of no a priori differences in small bowel transit or digestion of carbohydrates between patients with Crohn's disease of the colon and those with chronic ulcerative colitis. Therefore, the mechanism and significance of their accumulation, if present, remain unclear. The role of bile acids, other ions, or short-chain fatty acids in determining the composition and pathogenesis of the diarrhoea in colonic forms of inflammatory bowel disease must remain speculative until their concentrations in the faecal water of patients with inflammatory bowel disease are systematically studied.

Among ulcerative colitis patients, faecal analysis clearly distinguished between those with extensive involvement of the colon and those with inflammatory changes limited to the rectosigmoid. In the latter group, although water excretion was high, the concentrations of sodium, potassium, and chloride were nearly normal. These patients' mean $\left[\mathrm{K}^{+}\right] /\left[\mathrm{Na}^{+}\right]$ratio was, therefore, normal. In these ulcerative proctitis patients, although a difference in rectal transport processes can be demonstrated by in vivo rectal dialysis, ${ }^{16}$ overall colonic function as judged by faecal analysis appears to be preserved. This is consistent with studies using total colonic perfusion in similar groups of patients. ${ }^{16} \mathrm{~A}$ particular advantage of our method, then, is that it allows a clear separation between patients with ulcerative proctitis and those with more extensive chronic ulcerative colitis.

If our findings can be confirmed by a prospective study performed with proper control or analysis of diet, the results may allow a non-invasive approach to the diarrhoea of inflammatory bowel disease. Although we used careful clinical, radiographic, endoscopic, and pathological correlations to separate our groups into Crohn's disease of the colon and chronic ulcerative colitis and to exclude ileal involvement, there are inherent limitations to this current 'state of the art'. Radiographs often underestimate extent of disease, especially in Crohn's disease, and even our requirement that our clinicians, radiologists, and pathologists agree does not exclude misclassification or subtle anatomical or functional involvement of other segments of the large or small intestine. Evaluation of the complete ionic composition of faecal effluent from patients with inflammatory bowel disease may allow separation of these patients into groups based on these findings alone. This may be useful in understanding the pathophysiology of the diarrhoea in each group, suggesting and evaluating new modes of therapy for this distressing symptom, and in assessing the severity and extent of recurrence of the inflammatory process.

The authors wish to thank Dr Mark Dreyer and Dr J Donald Ostrow for helpful critical review of the manuscript, Dr Robert Riddell for review of the pathological material, and Dr E Lubbat, Dr T Neumann, and Dr J Wieland for allowing their patients to be included in this study.

\section{References}

1 Margulis AR, Goldberg HI, Lawson TL, et al. The overlapping spectrum of ulcerative and granulomatous colitis: A roentgenographic-pathologic study. Am J Roentgenol $1971 ; 113: 325-34$.

2 Schacter H, Goldstein J, Rappaport H, et al. Ulcerative and 'Granulomatous' colitis-validity of differential diagnostic criteria. Ann Intern Med 1970; 72:841-51.

3 Laufer I, Costopoulos L. Early lesion of Crohn's disease. Am J Roentgenol 1978; 130:307-11.

4 Marshak RH, Lindner AE. Ulcerative and granulomatous colitis. J Mt Sinai Hosp 1966; 38:444-502.

5 Price AB. Overlap in the spectrum of non-specific inflammatory bowel disease of unknown etiology. Gastroenterology 1975; 68:591-600.

6 Price AB, Morson BC. Inflammatory bowel disease: the surgical pathology of Crohn's disease and ulcerative colitis. Human Pathol 1975; 6:7-29.

7 Yardley JH, Donowitz M. Colo-rectal biopsy in inflammatory bowel disease. In: Yardley JH, ed. The gastrointestinal tract. Baltimore: Williams and Wilkins, 1977: 50-94.

8 Van de Kamer JH, ten BokkelHuinink H, Weyers HA. Rapid method for the determination of fat in feces. $J$ Biol Chem 1949; 177:347-55.

9 Krejs GH, Hendler RS, Fordtran JS. Diagnostic and patho-physiologic studies in patients with chronic diarrhea in secretory diarrhea. In: Field M, Fordtran JS, Schultz SG, eds. Secretory diarrhea. American Physiological Society. Bethesda, 1980:141-53.

10 Wrong O, Metcalfe-Gibson A, Morrison RBI, NG ST, Howard AV. In vivo dialysis of faeces as a method of stool analysis. I. Technique and results in normal subjects. Clin Sci 1965; 28:357-75.

11 Bustos F, et al. Fecal acidorrhea. N Engl J Med 1971; 284:295-8.

12 Snedecor GE, Cochran WG. Statistical methods Ames, Iowa: Iowa State University Press, 1967.

13 Harris J, Shield R. Absorption and secretion of water and electrolytes by the intact human colon in diffuse untreated procto-colitis. Gut 1970; 11:27-33.

14 Head LH, Heaton JW, Kivel RM. Absorption of water and electrolytes in Crohn's disease of the colon. Gastroenterology 1969; 56:57-9. 
15 Edmonds CJ. Absorption of sodium and water by the human rectum measured by a dialysis method. Gut 1971; 12:356-62.

16 Rask-Madsen J. Functional alterations in ulcerative colitis. In: Robinson, JWL, et al. Intestinal ion transport. Baltimore: University Park Press, 1975.

17 Van trappen G, Ghoos Y, Rutgeerts P, Janssens J. Bile acid studies in uncomplicated Crohn's disease. Gut 1977; 18:730-5.

18 Lenz K. An evaluation of the 'breath test' in Crohn's disease. Scand J Gastroenterol 1975; 10:665-71.

$19 \mathrm{Krag}$ B, Krag E. Regional ileitis (Crohn's disease) II. Electrolyte and water movement in the ileum during perfusion with bile acids. Scand J Gastroenterol 1976; 11:487-90.

20 Miettinen TA. The role of bile salts in diarrhea of patients with ulcerative colitis. Gut $1971 ; 12: 632-5$.

21 Hofmann AF, Poley JR. Role of bile acid malabsorption in pathogenesis of diarrhea and steatorrhea in patients with ileal resection. Gastroenterology 1972; 62:818-34.

22 Soergel KH, et al. Absorption of short-chain fatty acids by the colon. Gastroenterology 1980; 78:1500-07.

23 McNeil NI, Cummings。JH, James WPT. Short-chain fatty acid absorption by the human large intestine. Gut 1978; 19:819-22.

24 Bond JH, Levitt MD. Fate of soluble carbohydrate in the colon of rats and man. J Clin Invest 1976; 57:1 158-64. 